\title{
Oxidation of Quercetin by Salivary Components I. Salivary Peroxidase-Dependent Oxidation of Quercetin and Characterization of the Oxidation Products
}

\author{
Umeo TAKAHAMA, ${ }^{1}$ Sachiko HIROTA, ${ }^{2}$ Takahiro NishiOKA ${ }^{1}$ and Kunijiro YoshitAmA ${ }^{3}$ \\ ${ }^{1}$ Kyushu Dental University, Kitakyushu, Fukuoka 803-8580, Japan \\ ${ }^{2}$ Department of Nutritional Science, Kyushu Women's University, Kitakyushu, Fukuoka 807-8586, Japan \\ ${ }^{3}$ Department of Biological Science, Kumamoto University, Kumamoto, Kumamoto 860-8555, Japan
}

Received October 4, 2001; Accepted February 1, 2002

\begin{abstract}
Quercetin glucosides ingested as components of a foodstuff can be transformed to quercetin, and the quercetin is oxidized by peroxidase in the oral cavity. One objective of this study was the characterization of the oxidation products. Although both salivary peroxidase and myeloperoxidase are contained in whole saliva, salivary peroxidase is mainly involved in the oxidation in the saliva. As the oxidation products, $2,3,5,7,3^{\prime}, 4^{\prime}$-hexahydroxyflavanone-like compound and two isomers of a compound, which was transformed to quercetin and the above flavanone by a $\mathrm{HCl} / \mathrm{heat}-$ treatment, were isolated. 3,4-Dihydroxybenzoic acid and 2,4,6-trihydroxyphenylglyoxylic acid were also detected in the oxidation products. When dialyzed saliva was used, the salivary peroxidase-dependent oxidation of quercetin and the formation of the oxidation products were partly inhibited by $1 \mathrm{~mm}$ thiocyanate which was a substrate for the peroxidase in the oral cavity. The mechanism and the significance of salivary peroxidase-dependent oxidation of quercetin in the oral cavity are discussed.
\end{abstract}

Keywords: oxidation products, quercetin, salivary peroxidase, saliva

Polyphenols including flavonol quercetin have antioxidative activities (Rice-Evans \& Miller, 1997; Terao \& Piskula, 1997), and metabolism of these compounds in liver and colonic bacteria has been studied (Hollman \& Katan, 1997). Since polyphenols are normally ingested by mouth as vegetables and fruits, elucidation of their metabolism in the oral cavity is also important. In previous papers, we reported that when onion soup, which contains quercetin glucosides (Hirota et al., 1998, 1999), is ingested, the glucosides are hydrolyzed to the aglycone quercetin, and that quercetin is degraded in the oral cavity (Hirota et al., 2001). The degradation is also observed when quercetin is added to collected saliva with and without externally added $\mathrm{H}_{2} \mathrm{O}_{2}$. Since peroxidases in the oral cavity can catalyze the oxidative degradation of quercetin, the oxidation reaction may, in part, participate in scavenging $\mathrm{H}_{2} \mathrm{O}_{2}$ (Hirota et al., 2001). If quercetin is oxidized by peroxidases in the oral cavity, characterization of the oxidation products is required. At present, the oxidation products of quercetin when the flavonol is oxidized by peroxidases in the oral cavity has not been studied, although there are reports on these products when oxidized by plant peroxidase (Barz et al., 1985; Schreier \& Miller, 1985; Takahama \& Hirota, 2000) and oxidase (Hösel \& Barz, 1972). Figure 1 shows chemical structures of quercetin (1) and some of the stable oxidation products (2-5). 3,4-Dihydroxybenzoic acid (2) and 2,4,6-trihydroxyphenylglyoxylic acid (3) are the degradation products formed during the oxidation (Barz et al., 1985; Schreier \& Miller, 1985). $2,3,5,7,3^{\prime}, 4^{\prime}$-Hexahydroxyflavanone (4) is the initial stable oxidation product when oxidized by horseradish peroxidase (Schreier

Abbreviations: HPLC, high performance liquid chromatography

E-mail: takahama@kyu-dent.ac.jp
\& Miller, 1985) and when oxidized by oxidase isolated from Cicer (Hösel \& Barz, 1972). 2,3-Epoxy-2-(3,4-dihydroxyphenyl)-3-[4O-[2-(3-hydroxyphenyl)-3,5,7]-trihydroxy-4H-1-benzopyran-4-onyl]-5,7-dihydroxy-4H-1-benzopyran-4-one (5) was reported to be a horseradish peroxidase-dependent oxidation product of quercetin by Schreier \& Miller (1985).

One objective of the present study was characterization of the oxidation products of quercetin when the flavonol was oxidized by peroxidases in saliva. Since leukocytes are normally present in the oral cavity (Al-Essa et al., 1994; Yamamoto et al., 1991), collected whole saliva usually contains not only salivary peroxidase but also myeloperoxidase from the leukocytes. Salivary peroxidase is a heme protein and can catalyze $\mathrm{H}_{2} \mathrm{O}_{2}$-dependent oxidation of $\mathrm{SCN}^{-}$and $\mathrm{I}^{-}$but not $\mathrm{Cl}^{-}$(Tenovuo, 1989), and these anions are salivary components. In addition, the peroxidase can use other substrates for its reaction (guaiacol and pyrogallol as electron donors and sodium percarbonate, urea peroxide and benzoyl peroxide as peroxides) (Tenovuo, 1989; Makinen, 1989). Myeloperoxidase catalyzes $\mathrm{H}_{2} \mathrm{O}_{2}$-dependent oxidation of $\mathrm{Cl}^{-}$to $\mathrm{OCl}^{-}$. The other objective was elucidation of whether both these peroxidases participate in the oxidation of quercetin. Significance of the oxidation of quercetin is discussed based on the results obtained in this study.

\section{Materials and Methods}

Reagents Horseradish peroxidase (type II), myeloperoxidase from human leukocytes and monochlorodimedon were obtained from Sigma (St. Louis, MO). Quercetin and 3,4-dihydroxybenzoic acid were from Wako Pure Chem. Ind. (Osaka). 2,4,6Trihydroxyphenylglyoxylic acid was synthesized by the method reported by Hargreaves et al. (1958). 
<smiles>O=c1c(O)c(-c2ccc(O)c(O)c2)oc2cc(O)cc(O)c12</smiles>

(1)<smiles>O=C(O)c1ccc(O)c(O)c1</smiles>

(2)

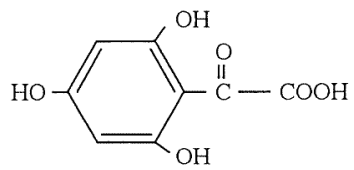

(3)<smiles>O=C1c2c(O)cc(O)cc2OC(O)(c2ccc(O)c(O)c2)C1O</smiles>

(4)<smiles></smiles>

( 5 )

Fig. 1. Chemical structures of compounds found in text.

Preparation of saliva Whole mixed saliva $(5 \mathrm{ml})$ was collected from four healthy volunteers by chewing parafilm at about $9 \mathrm{pm}$. The $\mathrm{pH}$ of collected saliva was 7.6-7.8. Three saliva preparations, referred to as i) filtered, ii) centrifuged and iii) dialyzed saliva, were prepared from the collected saliva. Filtered saliva, which was prepared by filtration of the saliva through a layer of nylon filter net (mesh 300, $50 \mu \mathrm{m}$ ), included a salivary component thiocyanate (Ferguson, 1989) and cellular components like detached epithelial cells and leukocytes. Centrifuged saliva was prepared by centrifugation of the collected saliva at $20,000 \times g$ for $10 \mathrm{~min}$; in this preparation, thiocyanate was included. To prepare dialyzed saliva, collected whole saliva $(5 \mathrm{ml})$ was centrifuged at $20,000 \times \mathrm{g}$ for $10 \mathrm{~min}$, and then dialyzed against $2 l$ of $10 \mathrm{mM}$ sodium phosphate $(\mathrm{pH} 7.6)$ for $10-12 \mathrm{~h}$ at about $4^{\circ} \mathrm{C}$. The dialyzed saliva, of which thiocyanate concentration was diluted 400 fold, was centrifuged $(20,000 \times g, 10 \mathrm{~min})$ to use for experiments. Since essentially the same results were obtained independent of saliva that was collected from the different persons, typical data were presented.

Oxidation of quercetin The above three saliva preparations (filtered, centrifuged and dialyzed saliva) were used for
$\mathrm{H}_{2} \mathrm{O}_{2}$-dependent oxidation of quercetin. When filtered or centrifuged saliva was used, the reaction mixture was composed of 50 $\mu \mathrm{M}$ quercetin and various concentrations of $\mathrm{H}_{2} \mathrm{O}_{2}$ in $0.5 \mathrm{ml}$ of the saliva. Reactions were started by adding $\mathrm{H}_{2} \mathrm{O}_{2}$ and terminated by extracting quercetin with $2 \mathrm{ml}$ of ethyl acetate after defined periods of incubation. The extraction was repeated three times and the extracts were combined (fraction 1). After the above ethyl acetate extraction, $\mathrm{pH}$ of the remaining water solution was adjusted to 3.0 by adding $2.5 \mathrm{M} \mathrm{HCl}$ to extract with $2 \mathrm{ml}$ of ethyl acetate (fraction 2). Ethyl acetate of each fraction was evaporated with a rotary evaporator and the residue of each fraction was dissolved in $0.5 \mathrm{ml}$ of a mixture of methanol and $25 \mathrm{mM} \mathrm{K \textrm {K } _ { 2 }} \mathrm{PO}_{4}$ $(1: 1, \mathrm{v} / \mathrm{v})$. In fraction 1 , at least three major oxidation products (in the following, CX, QX-1 and QX-2) and quercetin were detected and in fraction 2, CX was detected by HPLC (see below). The reason the reaction mixture was extracted by the two steps was that in the saliva preparations, nitrite, which oxidized quercetin to $\mathrm{CX}$ under acidic conditions (below pH 3), was contained at about $180 \mu \mathrm{M}$ as reported by Ferguson (1989). CX was quite slowly oxidized at $\mathrm{pH} 3$.

When dialyzed saliva was used, the reaction mixture contained $50 \mu \mathrm{M}$ quercetin, various concentrations of $\mathrm{H}_{2} \mathrm{O}_{2}$ and \pm 1 $\mathrm{mM} \mathrm{NaSCN}$ in $0.1 \mathrm{ml}$ of dialyzed saliva. Reactions were started by adding $\mathrm{H}_{2} \mathrm{O}_{2}$ and terminated by adding $0.1 \mathrm{ml}$ of methanol after defined periods of incubation. The mixture (50\% methanol) was applied to an HPLC column.

HPLC HPLC was performed using a reverse phase column $(6 \mathrm{~mm}$ i.d. $\times 15 \mathrm{~cm})$ (CLC-ODS, Shimadzu, Kyoto) combined with a spectrophotometric detector with a photodiode array (SPD M10A, Shimadzu). Mobile phase used for the separation of $\mathrm{CX}$ was the mixture of methanol and $25 \mathrm{mM} \mathrm{KH} \mathrm{KO}_{4}(1: 3$, v/ $\mathrm{v}$ ) and that used for the separation of quercetin, QX-1 and QX-2 was the mixture of methanol and $25 \mathrm{mM} \mathrm{KH}_{2} \mathrm{PO}_{4}(3: 2, \mathrm{v} / \mathrm{v})$. Flow rate of the mobile phases was $1 \mathrm{ml} \mathrm{min}^{-1}$.

Large-scale preparation Components, of which retention times and absorption spectra were identical with CX and QXs (QX-1 plus QX-2), were also formed when quercetin was oxidized by horseradish peroxidase as reported by Schreier \& Miller (1985). Therefore, large-scale preparations of CX and QXs were made as follows. The reaction mixture $(300 \mathrm{ml})$ contained 100 $\mu \mathrm{M}$ quercetin, $30 \mu \mathrm{g}$ horseradish peroxidase and $80 \mu \mathrm{M} \mathrm{H}_{2} \mathrm{O}_{2}$ in $0.1 \mathrm{M}$ sodium phosphate ( $\mathrm{pH}$ 7.8). The mixture was incubated for $1 \mathrm{~min}$ and then acidified with $3 \mathrm{ml}$ of $2.5 \mathrm{M} \mathrm{HCl}$. The acidic solution was extracted with $200 \mathrm{ml}$ of ethyl acetate twice. The above procedures were repeated three times. Each ethyl acetate extract was combined and ethyl acetate was evaporated with a rotary evaporator at about $30^{\circ} \mathrm{C}$. The residue was dissolved in $2 \mathrm{ml}$ of methanol and applied to a Sephadex LH-20 column $(2 \mathrm{~cm}$ i.d. $\times 35 \mathrm{~cm}$ ). CX and QXs were eluted with methanol as reported by Schreier and Miller (1985). The obtained CX and QXs were further purified with the above chromatography. The yields of CX and QXs were about $3 \mathrm{mg}$ and $5 \mathrm{mg}$, respectively. Since CX and QXs were suggested to be 4- and 5-like compounds, respectively (see Results), molar absorption coefficients of $4\left[14 \mathrm{~mm}^{-1}\right.$ $\mathrm{cm}^{-1}$ at $288 \mathrm{~nm}$ in methanol (Hauteville et al., 1979)] and 5 [10 $\mathrm{mM}^{-1} \mathrm{~cm}^{-1}$ at $360 \mathrm{~nm}$ in methanol (Schreier \& Miller, 1985)] were used to estimate the concentrations of CX and QXs.

Determination of enzyme activities Peroxidase activity was measured using a double-beam spectrophotometer (557, 

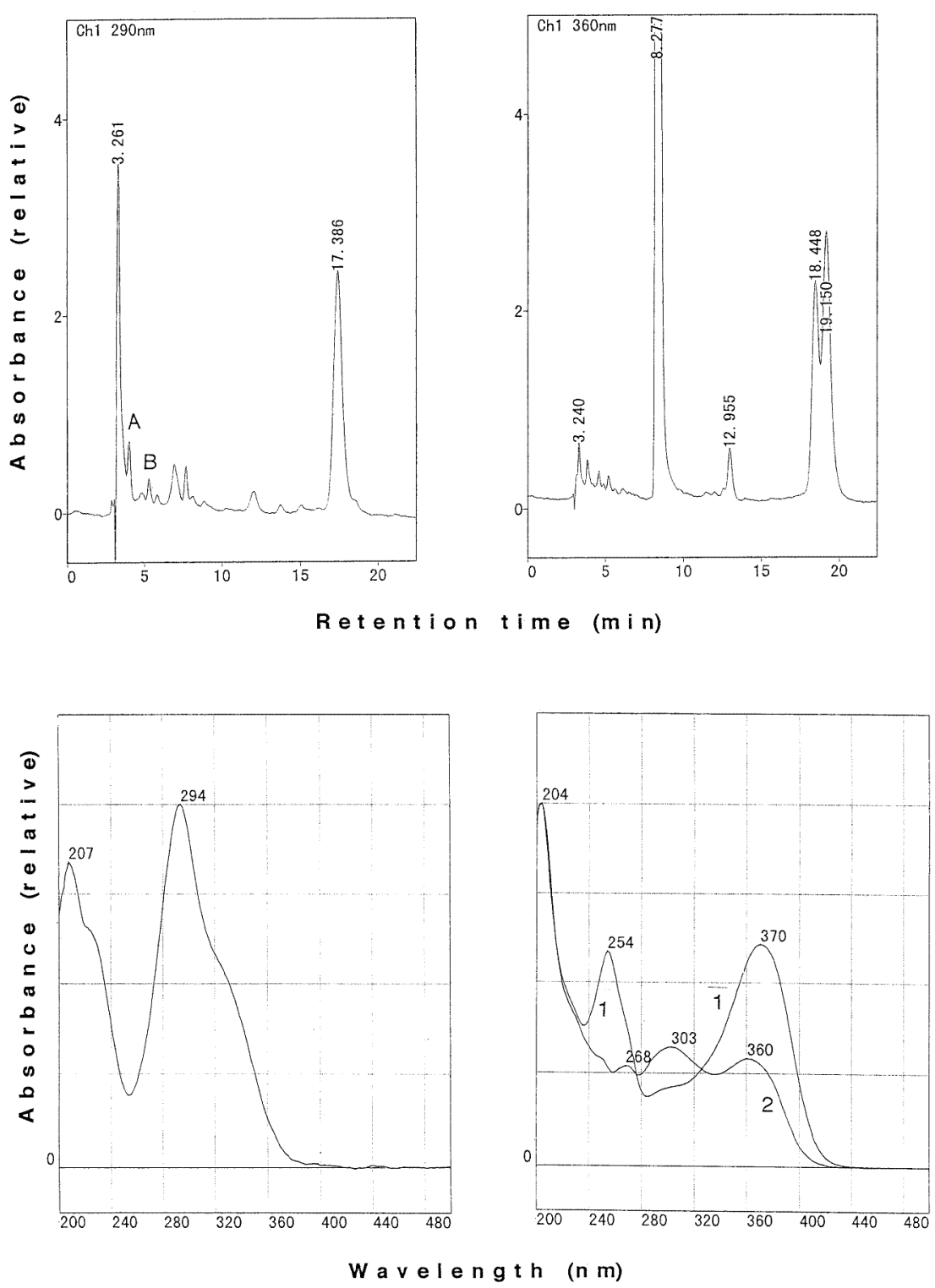

Fig. 2. HPLC elution profiles of oxidation products of quercetin. The reaction mixture $(0.5 \mathrm{ml})$ contained $0.5 \mathrm{ml}$ of centrifuged saliva, $50 \mu \mathrm{M}$ quercetin and $100 \mu \mathrm{M} \mathrm{H} \mathrm{O}_{2}$. Thirty seconds after the addition of $\mathrm{H}_{2} \mathrm{O}_{2}, 2 \mathrm{ml}$ of ethyl acetate was added to extract quercetin, CX and QXs. The extraction was repeated three times and the extracts were combined (fraction 1). Fifty microliters of $2.5 \mathrm{M} \mathrm{HCl}$ was added to the remaining aqueous solution to extract remaining CX with 2 $\mathrm{ml}$ of ethyl acetate (fraction 2). After evaporation of ethyl acetate, the residue of each fraction was dissolved in $0.5 \mathrm{ml}$ of a mixture of methanol and $25 \mathrm{~mm}$ $\mathrm{KH}_{2} \mathrm{PO}_{4}(1: 1, \mathrm{v} / \mathrm{v})$. Twenty-five microliters of the solution was applied to an HPLC column. Upper panels: HPLC profiles. Left, fraction 2 (2,4,6-trihydroxyphenylglyoxylic acid, peak A; 3,4-dihydroxybenzoic acid, peak B; CX, $17.3 \mathrm{~min}$ ); right, fraction 1 (quercetin, 8.2 min; QXs, 18.4 and 19.1 min). Lower panels: Absorption spectra. Left, CX; right, quercetin (curve 1) and QXs (curve 2).

Hitachi, Tokyo). Activities of peroxidase of saliva and myeloperoxidase were measured in the reaction mixture $(1 \mathrm{ml})$ that contained $0.1 \mathrm{ml}$ of filtered or centrifuged saliva or $50 \mathrm{ng}$ of myeloperoxidase, $0.1 \mathrm{mM} \mathrm{H}_{2} \mathrm{O}_{2}, 100 \mathrm{mM} \mathrm{NaCl}$ and a substrate $(0.1$ $\mathrm{mM}$ monochlorodimedon, $30 \mathrm{mM}$ guaiacol or $0.05 \mathrm{~mm}$ quercetin) in $0.1 \mathrm{M}$ sodium phosphate ( $\mathrm{pH} 7.0)$. Rates of oxidation of guaiacol and quercetin were measured by the absorbance increase at $470 \mathrm{~nm}$ (molar absorption coefficient, $26.6 \mathrm{mM}^{-1} \mathrm{~cm}^{-1}$ ) and the absorption decrease at $370 \mathrm{~nm}$ (molar absorption coefficient, $18 \mathrm{~mm}^{-1} \mathrm{~cm}^{-1}$ ), respectively. Chlorination of monochlorodimedon, which proceeds by $\mathrm{OCl}^{-}$formed by myeloperoxidase, was measured by absorption decrease at $290 \mathrm{~nm}$ (molar absorption coefficient, $19 \mathrm{~mm}^{-1} \mathrm{~cm}^{-1}$ ).

\section{Results}

Oxidation products Figure 2 shows HPLC elution profiles of fractions 1 and 2 prepared after oxidation of quercetin by centrifuged saliva. A component, which was referred to as CX (retention time, $17.3 \mathrm{~min}$ ) was detected in fraction 2 (upper left) and CX had peaks at 207 and $294 \mathrm{~nm}$ in the mobile phase (lower left). In addition, peaks A and B were also detected in fraction 2; these were identified as $\mathbf{3}$ and $\mathbf{2}$, respectively, by comparing retention times and absorption spectra with the standard compounds as reported previously (Takahama \& Hirota, 2000). Compounds $\mathbf{2}$ and $\mathbf{3}$ have been reported to be plant peroxidasedependent oxidation products of quercetin by Barz et al. (1985) and Schreier \& Miller (1985). Quercetin (retention time, 8.2 min) and two components, which were referred to as QX-1 
(retention time, $18.4 \mathrm{~min}$ ) and QX-2 (retention time, $19.1 \mathrm{~min}$ ), were detected in fraction 1 (upper right). The absorption spectrum of QX-1 was identical with that of QX-2 which had peaks at 204, 268, 303 and $360 \mathrm{~nm}$ (lower right). Only small amounts of the above oxidation products of quercetin were detected when quercetin was incubated in $100 \mu \mathrm{M} \mathrm{H}_{2} \mathrm{O}_{2}$ in the absence of saliva (data not shown).

Characterization of $C X$ and $Q X s$ Retention time of isolated CX was identical with that of CX in Fig. 1. An absorption spectrum of isolated CX in methanol (peak, $288 \mathrm{~nm}$; shoulder, $330 \mathrm{~nm}$ ) was identical with that of 4 (Hauteville et al., 1979) and effects of $\mathrm{pH}$ on the absorption spectrum of CX (peaks, $290 \mathrm{~nm}$ at $\mathrm{pH} 4.6$ and $325 \mathrm{~nm}$ at $\mathrm{pH} 7.0$ ) were also similar to those of $\mathrm{pH}$ on the absorption spectrum of $\mathbf{4}$ which was reported by Hauteville et al. (1979) and Hösel \& Barz (1972). When isolated CX was oxidized in the reaction mixture $(1 \mathrm{ml})$ that contained 0.3 $\mathrm{mM} \mathrm{CX}, 0.1 \mathrm{mM} \mathrm{H}_{2} \mathrm{O}_{2}$ and $0.1 \mu \mathrm{g}$ of horseradish peroxidase in $0.1 \mathrm{M} \mathrm{NaH}_{2} \mathrm{PO}_{4}(\mathrm{pH} 4.6$ ) for 1 and $10 \mathrm{~min}, 2$ and $\mathbf{3}$ were detected as the main oxidation products by HPLC, indicating that $\mathrm{CX}$ had a flavonoid structure with unaffected $\mathrm{A}$ and $\mathrm{B}$ rings of quercetin. From these results, $\mathrm{CX}$ is beliebed to be a 4-like compound.

The isolated QXs were separated to QX-1 and QX-2 by HPLC when a mixture of methanol and $25 \mathrm{mM} \mathrm{KH}_{2} \mathrm{PO}_{4}(3: 2, \mathrm{v} /$
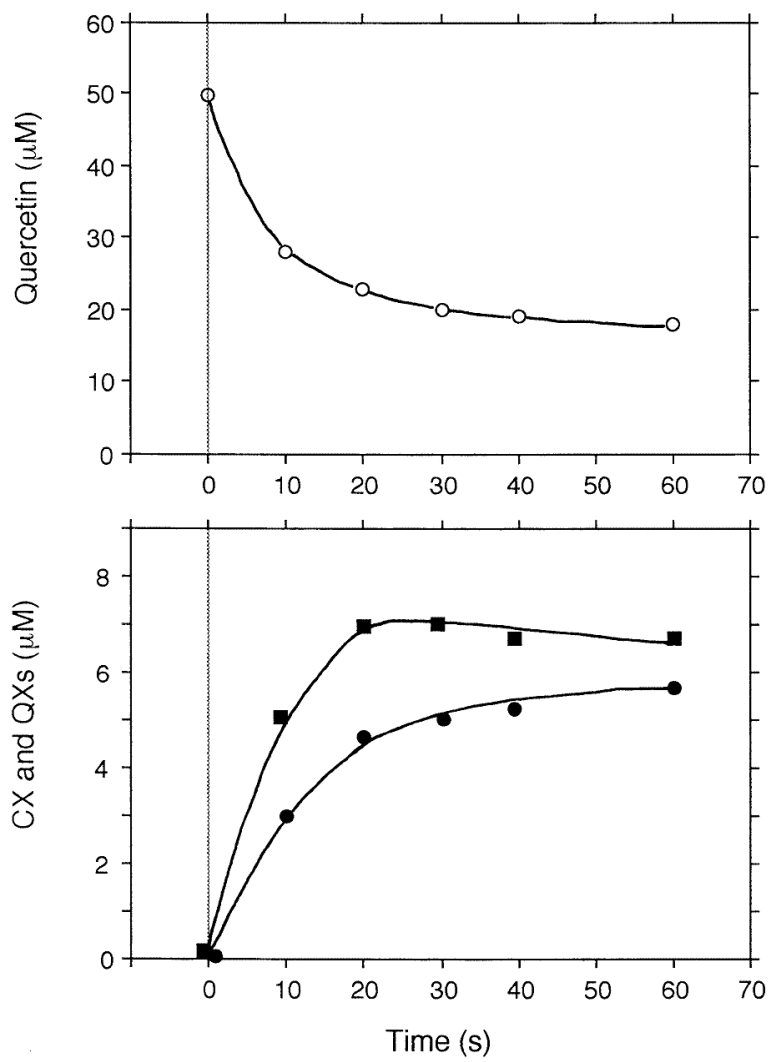

Fig. 3. Time courses of $\mathrm{H}_{2} \mathrm{O}_{2}$-dependent oxidation of quercetin by centrifuged saliva. The reaction mixture $(0.5 \mathrm{ml})$ contained $0.5 \mathrm{ml}$ of filtered saliva and $50 \mu \mathrm{M}$ quercetin. Reactions were started by adding $100 \mu \mathrm{M} \mathrm{H}_{2} \mathrm{O}_{2}$ and reaction mixtures were extracted with $2 \mathrm{ml}$ ethyl acetate three times after defined periods of incubation (fraction 1). Fifty microliters of $2.5 \mathrm{M} \mathrm{HCl}$ was added to the remaining water solution and CX was extracted by $2 \mathrm{ml}$ of ethyl acetate (fraction 2). The amounts of quercetin, CX and QXs were calculated from HPLC data of fractions 1 and 2 as described in Materials and Methods. Upper panel, quercetin; lower panel, CX and QXs. Circles, CX; squares, QXs. v) was used as the mobile phase. Both QX-1 and QX-2 had peaks at 268, 303 and $360 \mathrm{~nm}$ as shown in Fig. 2, suggesting that the structure of QX-1 is similar to that of QX-2 and that QXs have a quercetin-like moiety. Effects of various shift reagents (sodium acetate, sodium molybdate, $\mathrm{Na}_{3} \mathrm{BO}_{3}$ and $\mathrm{AlCl}_{3} \pm \mathrm{HCl}$ ) (Markham, 1989) on the absorption spectrum were studied. The results showed the presence of free 7-hydroxyl groups, $o$-dihydroxyl groups, 4-keto groups and 3- and/or 5-hydroxyl groups. To obtain further information on QXs, $1 \mathrm{ml}$ of $0.21 \mathrm{mM} \mathrm{QXs}$ was incubated for $20 \mathrm{~min}$ in $1 \mathrm{M} \mathrm{HCl}$ at about $95^{\circ} \mathrm{C}$, and then the acidic solution was extracted with ethyl acetate. After evaporation of the ethyl acetate, the residue was dissolved in methanol and analyzed by HPLC. Quercetin, CX, 2 and $\mathbf{3}$ were identified by their retention times and absorption spectra. The identification of these compounds suggested that QXs were composed of quercetin and a component similar to CX; compounds $\mathbf{2}$ and $\mathbf{3}$ may be degradation products of the quercetin and/or the CX-like moieties. From the above data, we deduced that QXs are composed of two isomers of a 5-like compound. Two isomers of $\mathbf{5}$ were isolated by Schreier and Miller (1985) from the horseradish peroxidase-dependent oxidation products of quercetin.

Kinetics of quercetin oxidation Figure 3 shows time courses of oxidation of quercetin and formation of CX and QXs when $0.1 \mathrm{mM} \mathrm{H}_{2} \mathrm{O}_{2}$ was added to centrifuged saliva in the pres-
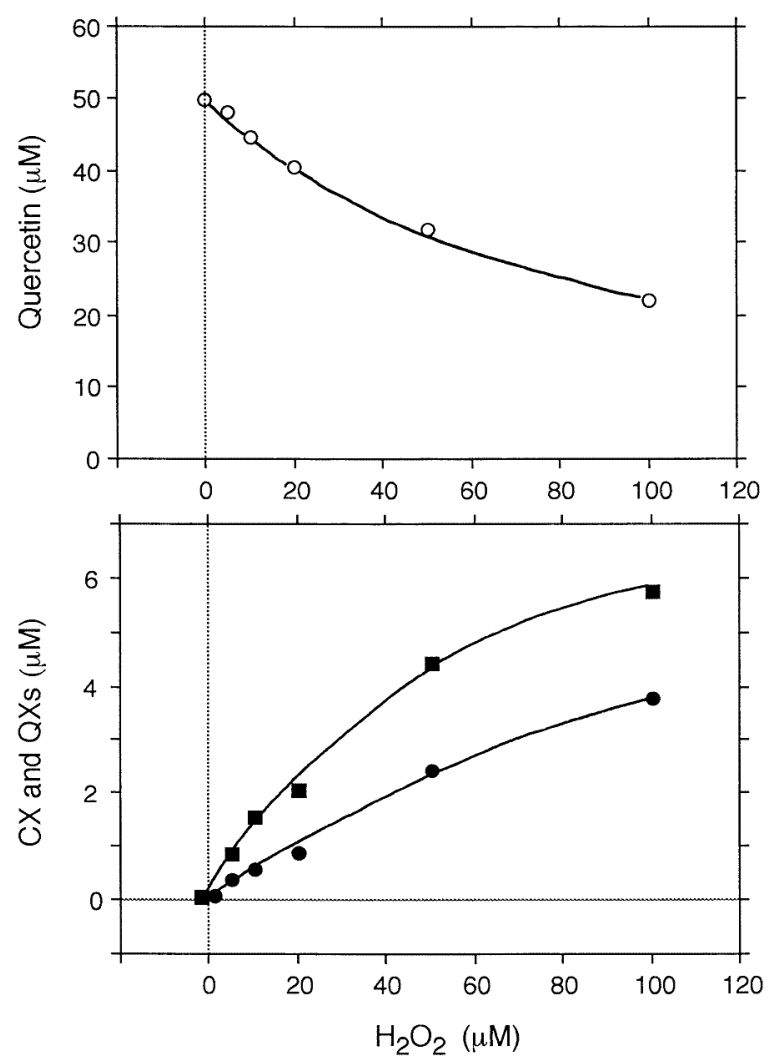

Fig. 4. Effects of $\mathrm{H}_{2} \mathrm{O}_{2}$ concentration on oxidation of quercetin by centrifuged saliva. The reaction mixture $(0.5 \mathrm{ml})$ contained $0.5 \mathrm{ml}$ of filtered saliva and $50 \mu \mathrm{M}$ quercetin. Reactions were started by adding $\mathrm{H}_{2} \mathrm{O}_{2}$ and reaction mixtures were extracted with $2 \mathrm{ml}$ ethyl acetate three times after $10 \mathrm{~s}$ of incubation (fraction 1). Fifty microliters of $2.5 \mathrm{M} \mathrm{HCl}$ was added to the remaining water solution and $\mathrm{CX}$ was extracted by $2 \mathrm{ml}$ of ethyl acetate (fraction 2). The amounts of quercetin, CX and QXs were calculated from HPLC data of fractions 1 and 2 as described in Materials and Methods. Upper panel, quercetin; lower panel, CX and QXs. Circles, CX; squares, QXs. 
ence of $50 \mu \mathrm{M}$ quercetin. CX was contained in fractions 1 and 2; the total amounts are shown in the figure. Since QX-1 was an isomer of QX-2, the sum of QX-1 plus QX-2 was expressed. Small amounts of CX and QXs were formed when quercetin was added to the centrifuged saliva without addition of $\mathrm{H}_{2} \mathrm{O}_{2}$ (time zero), and the amounts were increased when $\mathrm{H}_{2} \mathrm{O}_{2}$ was added. Not all quercetin was oxidized during the incubation periods. Effects of $\mathrm{H}_{2} \mathrm{O}_{2}$ concentration on the formation of CX and QXs were also examined (Fig. 4). As the concentration of $\mathrm{H}_{2} \mathrm{O}_{2}$ was increased, formation of these oxidation products was increased. Essentially the same results were obtained using filtered saliva (data not shown).

To study the effects of thiocyanate on $\mathrm{H}_{2} \mathrm{O}_{2}$-dependent oxidation of quercetin, dialyzed saliva, of which the thiocyanate concentration was low, was used. Figure 5 shows time courses of oxidation of quercetin and formation of $\mathrm{CX}$ in the presence (closed symbols) and absence (open symbols) of $1 \mathrm{mM}$ of thiocyanate. During incubation of quercetin with 25 or $100 \mu \mathrm{M} \mathrm{H}_{2} \mathrm{O}_{2}$, the concentration of CX was increased. More than $90 \%$ of quercetin was oxidized when $100 \mu \mathrm{M} \mathrm{H}_{2} \mathrm{O}_{2}$ was added. The oxidation of quercetin and the formation of $\mathrm{CX}$ was suppressed by $1 \mathrm{mM}$ thiocyanate. $\mathrm{H}_{2} \mathrm{O}_{2}$-dependent formation of QXs by dialyzed saliva was also inhibited by $1 \mathrm{mM}$ thiocyanate (data not shown). Effects of $\mathrm{H}_{2} \mathrm{O}_{2}$ concentration on the oxidation of quercetin by dialyzed saliva with $1 \mathrm{mM}$ thiocyanate were essentially the same
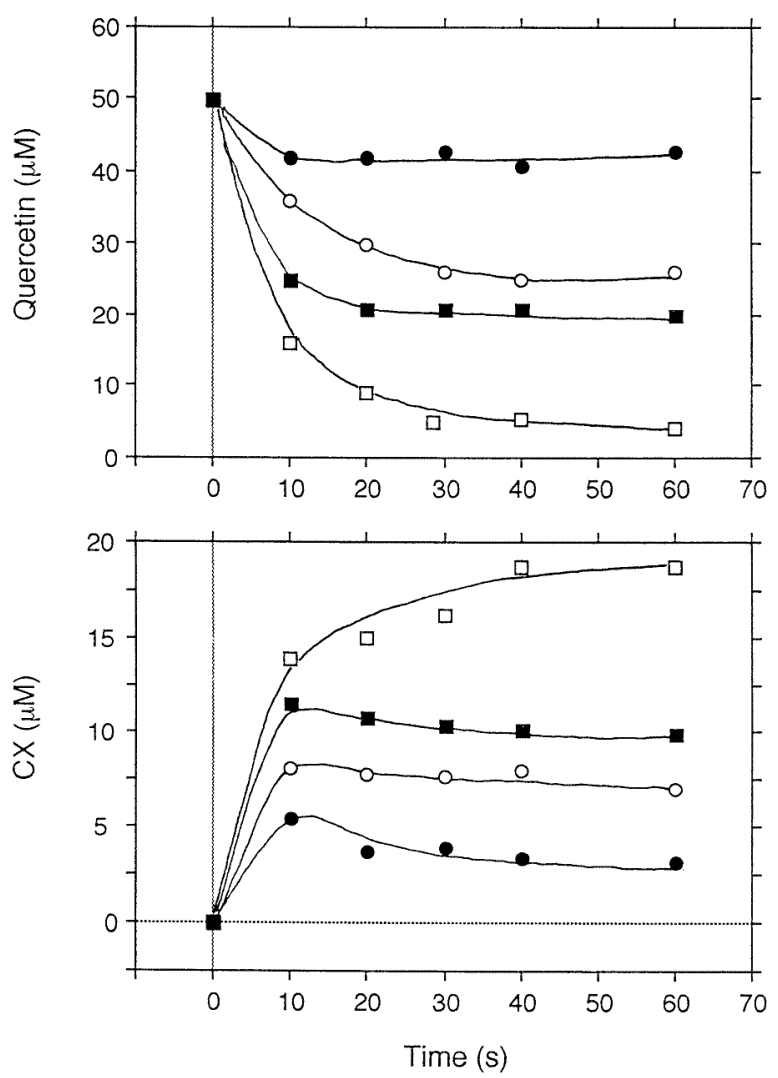

Fig. 5. Time courses of $\mathrm{H}_{2} \mathrm{O}_{2}$-dependent oxidation of quercetin by dialyzed saliva. The reaction mixture $(0.1 \mathrm{ml})$ contained $0.1 \mathrm{ml}$ of dialyzed saliva, $50 \mu \mathrm{M}$ quercetin and $\pm 1 \mathrm{~mm} \mathrm{NaSCN}$. Reactions were started by adding 25 and $100 \mu \mathrm{M} \mathrm{H}_{2} \mathrm{O}_{2}$ and reactions were terminated at defined periods by adding $0.1 \mathrm{ml}$ of methanol. Open circles, $25 \mathrm{~mm} \mathrm{H}_{2} \mathrm{O}_{2}$; closed circles, $25 \mu \mathrm{M}$

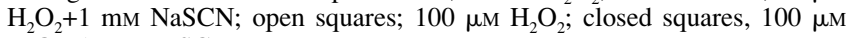
$\mathrm{H}_{2} \mathrm{O}_{2}+1 \mathrm{~mm}$ NaSCN.
Table 1. Activities of myeloperoxidase and peroxidases in saliva.

\begin{tabular}{|c|c|c|c|}
\hline Substrate & Quercetin & Guaiacol & $\mathrm{MCD}^{a)}$ \\
\hline Myeloperoxidase $\left(\mathrm{mmol} \mathrm{mg}^{-1}\right.$ protein $\left.\mathrm{min}^{-1}\right)$ & 0.34 & 0.32 & 0.106 \\
\hline Centrifuged saliva $\left(\mathrm{mM} \mathrm{ml}^{-1}\right.$ saliva $\left.\mathrm{min}^{-1}\right)$ & 0.25 & 0.34 & $-b)$ \\
\hline Filtered saliva $\left(\mathrm{mM} \mathrm{ml}^{-1}\right.$ saliva $\left.\mathrm{min}^{-1}\right)$ & 0.40 & 0.56 & 0.002 \\
\hline
\end{tabular}

as those of $\mathrm{H}_{2} \mathrm{O}_{2}$ concentration on the oxidation of quercetin by filtered saliva.

Participation of salivary peroxidase It is known that both salivary peroxidase derived from salivary glands and myeloperoxidase derived from leukocytes are contained in mixed whole saliva (Tenovuo, 1989). Therefore, we examined whether both of these peroxidases participated in the oxidation of quercetin. Myeloperoxidase catalyzed the oxidation of quercetin and guaiacol and the chlorination of monochlorodimedon at the rates shown in Table 1. No detectable chlorination of monochlorodimedon was observed in centrifuged saliva but the compound was slowly chlorinated by filtered saliva. The difference may be due to the presence and absence of leukocytes in the two saliva preparations. Quercetin and guaiacol were oxidized at high rates by centrifuged and filtered saliva. From these results, the activity of myeloperoxidase in filtered saliva was calculated to be about $1.6 \%$ by comparing rates of oxidation of quercetin and chlorination of monochlorodimedon, and about $1.1 \%$ by comparing rates of oxidation of guaiacol and chlorination of monochlorodimedon. It is known that salivary peroxidase does not oxidize $\mathrm{Cl}^{-}$to $\mathrm{OCl}^{-}$(Tenovuo, 1989).

\section{Discussion}

Saliva preparations used in this study contained salivary peroxidase as a major peroxidase (Table 1). Therefore, it is concluded that salivary peroxidase was a main particpant in the oxidation of quercetin by $\mathrm{H}_{2} \mathrm{O}_{2}$. Compounds 2 and $\mathbf{3}$ and 4- and 5-like compounds were formed by oxidation of quercetin by salivary peroxidase. These compounds have also been reported to be horseradish peroxidase-dependent oxidation products of quercetin (Barz et al., 1985; Schreier \& Miller, 1985). These results suggest that the mechanism of quercetin oxidation by salivary peroxidase is similar to the mechanism by horseradish peroxidase. Since the radical is the initial oxidation product of quercetin according to the mechanism of peroxidase-dependent oxidation of organic compounds, quercetin radical may be a mutual precursor of CX and QXs, because the time course of CX formation was similar to that of QX formation (Figs. 3 and 5). The similarities in the time courses between CX and QX formation suggest that QXs are not formed from CX; if QXs were formed from CX, there would be a lag phase for the formation of QXs. There was a difference between the amount of oxidized quercetin and that of formed CX plus QXs. This can be explained by not all of the quercetin radical being transformed to $\mathrm{CX}$ and QXs. Schreier and Miller (1985) reported that in addition to CX and QXs, other oxidation products including a flavonoid trimer are also formed as the oxidation products of quercetin.

Compounds $\mathbf{2}$ and $\mathbf{3}$ may be formed by oxidation of a CX-like compound. This is deduced from the data that the horseradish peroxidase-dependent oxidation products of CX were $\mathbf{2}$ and $\mathbf{3}$. 
Since 2 (Walker \& Stahman, 1955) as well as hypothiocyanate, which is a salivary peroxidase-dependent oxidation product of thiocyanate (Tenovuo, 1989) is an antimicrobial agent, 2 may be able to inhibit the growth of bacteria in the oral cavity. Further studies are required to elucidate the antimicrobial function of $\mathbf{2}$ as well as quercetin in the oral cavity. It has been reported that phenolics including phenolic acids and flavonols generally have antimicrobial activities (Reichling, 1999).

When $100 \mu \mathrm{M} \mathrm{H}_{2} \mathrm{O}_{2}$ was added to filtered and centrifuged saliva in the presence of $50 \mu \mathrm{M}$ quercetin, about $60 \%$ of the quercetin was oxidized (Fig. 3), whereas in dialyzed saliva, more than $90 \%$ of quercetin was oxidized under the same conditions (Fig. $5)$. The difference is assumed to be due to the presence or absence of thiocyanate, which is a normal component of saliva. This assumption is acceptable because thiocyanate inhibited the oxidation of quercetin by dialyzed saliva (Fig. 5). The inhibition may be due to competition between thiocyanate and quercetin for compound I of salivary peroxidase, which is formed by direct reaction between $\mathrm{H}_{2} \mathrm{O}_{2}$ and peroxidase, as discussed previously (Hirota et al., 2001). The inhibition of quercetin oxidation by thiocyanate also suggests that the oxidation product of thiocyanate, hypothiocyanate, does not rapidly oxidize quercetin at $\mathrm{pH}$ 7.6. If concentrations of thiocyanate in the oral cavity [normal concentration, 0.5-2.0 mM (Ferguson, 1989)] are significantly decreased under some conditions, the $\mathrm{H}_{2} \mathrm{O}_{2}$ scavenging function of dietary quercetin and other polyphenols becomes important. In addition to salivary peroxidase, myeloperoxidase can also contribute to the oxidation of quercetin if the number of leukocytes in the oral cavity is increased. If myeloperoxidase participates in the oxidation of quercetin, the flavonol may be oxidized by not only the compound I but also $\mathrm{OCl}^{-}$formed by the peroxidase. This is deduced from the results that quercetin was oxidized by both compound I of myeloperoxidase (data not shown) and by $\mathrm{OCl}^{-}$(Pincemail et al., 1988). Reactive oxygen species like $\mathrm{O}_{2}^{-}$ can also oxidize quercetin in the oral cavity if leukocytes in the oral cavity are activated. $\mathrm{O}_{2}^{-}$-dependent oxidation of flavonols has been reported by Bors et al. (1997) and Takahama (1987). Oxidation of quercetin by reactive oxygen species $\left(\mathrm{O}_{2}^{-}\right.$and $\mathrm{H}_{2} \mathrm{O}_{2}$ ) formed by salivary leukocytes is in progress.

\section{References}

Al-Essa, L., Niwa, M., Kohno, K. and Tsurumi, K. (1994). A proposal for purification of salivary polymorphonuclear leukocytes by combination of nylon mesh filtration and density-gradient method: a validation by superoxide- and cyclic AMP-generating responses. Life Sci., 55, PL333-338.

Barz, W., Köster, J., Weltring, K.-M. and Strack, D. (1985). Recent advances in the metabolism and degradation of phenolic compounds in plants and animals. Ann. Proc. Phytochem. Soc. Eur., 25, 307-347.

Bors, W., Heller, W. and Michel, C. (1997). The chemistry of flavonoids. In "Flavonoids in Health and Disease," ed. by C.A. RiceEvans \& L. Packer. Marcel Dekker, New York, pp. 111-136.

Ferguson, D.B. (1989). Salivary electrolytes. In "Human Saliva. Clinical Chemistry and Microbiology Vol I," ed. by J. Tenovuo. CRC Press, Boca Raton, pp. 75-99.

Hargreaves, K.R., McGookin, A. and Robertson, A. (1958). Polyhy- droxyphenylglyoxylic acids. J. Appl. Chem., 8, 273-285.

Hauteville, M., Chadenson, M. and Chopin, J. (1979). Un nouveau type de flavonoïdes naturels: les dihydroxy-2,5 flavanones. VI. Synthèse et étude structurale de trihydroxy-2,3,5 flavanones. Bull. Soc. Chim. Fr., 1979II, 125-131.

Hirota, S., Shimoda, T. and Takahama, U. (1998). Tissue and spatial distribution of flavonol and peroxidase in onion bulbs and stability of flavonol glucosides during boiling of the scales. J. Agric. Food Chem., 46, 3497-3502.

Hirota, S., Shimoda, T. and Takahama, U. (1999). Distribution of flavonols and enzymes participating in the metabolism in bulbs: mechanism of accumulation of quercetin and its glucosides in the abaxial epidermis. Food Sci. Technol. Res., 5, 384-387.

Hirota, S., Nishioka, T., Shimoda, T., Miura, K., Annsai, T. and Takahama, U. (2001). Quercetin glucosides are hydrolyzed to quercetin in human oral cavity to participate in peroxidase-dependent scavenging of hydrogen peroxide. Food Sci. Technol. Res., 7, 239-245.

Hollman, P.C.H. and Katan, M.B. (1997). Absorption, metabolism, and bioavailability of flavonoids. In "Flavonoids in Health and Disease," ed. by C.A. Rice-Evans \& L. Packer. Marcel Dekker, New York, pp. 483-521.

Hösel, W. and Barz, W. (1972). Enzymatic transformation of flavonols with a cell-free preparation from Cicer arietinum L. Biochim. Biophys. Acta, 261, 294-303.

Makinen, K.K. (1989). Salivary enzymes. In "Human Saliva. Clinical Chemistry and Microbiology Vol II," ed. by J. Tenovuo. CRC Press, Boca Raton, pp. 93-119.

Markham, K.R. (1989). Flavones, flavonols and their glycosides. In "Methods in Plant Biochemistry Vol. 1," ed. by J.B. Harborne. Academic Press, London, pp. 197-235.

Pincemail, J., Beby, C., Thirion, A., de Bruyn-Dister, M. and Goutier, R. (1988). Human myeloperoxidase activity is inhibited in vitro by quercetin. Comparison with three related compounds. Experimentia, 44, 450-453.

Reichling, J. (1999). Plant-microbe interactions and secondary metabolites with antiviral, antibacterial and antifungal properties. In "Functions of Plant Secondary Metabolites and Their Exploitation in Biotechnology, Vol. 3," ed. by M. Wink. Sheffield Academic Press, Sheffield (UK), pp. 187-273.

Rice-Evans, C.A. and Miller, N.J. (1997). Structure-antioxidant activity relationships of flavonoids and isoflavonoids. In "Flavonoids in Health and Disease," ed. by C.A. Rice-Evans \& L. Packer. Marcel Dekker, New York, pp. 199-219.

Schreier, P. and Miller, E. (1985). Studies on flavonoid degradation by peroxidase: quercetin. Food Chem., 17, 301-317.

Takahama, U. (1987). Oxidation products of keampferol by superoxide anion radical. Plant Cell Physiol., 28, 953-957.

Takahama, U. and Hirota, S. (2000). Deglucosidation of quercetin glucosides to the aglycone and formation of antifungal agents by peroxidase-dependent oxidation of quercetin on browning of onion scales. Plant Cell Physiol., 41, 1021-1029.

Tenovuo, J. (1989). Nonimmunoglobulin defense factors in human saliva. In "Human Saliva. Clinical Chemistry and Microbiology Vol II," ed. by J. Tenovuo. CRC Press, Boca Raton, pp. 55-91.

Terao, J. and Piskula, M.K. (1997). Flavonoids as inhibitors of lipid peroxidation in membranes. In "Flavonoids in Health and Disease," ed. by C.A. Rice-Evans \& L. Packer. Marcel Dekker, New York, pp. 277-293.

Yamamoto, M., Saeki, K. and Utsumi, K. (1991). Isolation of human salivary polymorphonuclear leukocytes and their stimulation-coupled responses. Arch. Biochem. Biophys., 289, 76-82.

Walker, J.C. and Stahman, M.A. (1955). Chemical nature of disease resistance in plants. Annu. Rev. Plant Physiol., 6, 351-366. 